\title{
FLOOD HAZARD ASSESSMENT USING PARTICIPATORY APPROACH AND WEIGHTED OVERLAY METHODS
}

\author{
T. Bibi ${ }^{1 *}$, F. Nawaz ${ }^{3 *}$, A. Abdul Rahman ${ }^{2}$, A. Latif ${ }^{4}$ \\ ${ }^{1}$ Institute of Geology, University of Azad Jamun and Kashmir, Muzaffarabad 13100, Pakistan \\ tehmina_khan79pk@hotmail.com \\ ${ }^{2} 3$ D GIS Lab,Faculty of Built Environment and Surveying, Universiti Teknologi Malaysia, Skudai 81310, Johor, Malaysia -, \\ alias.fksg@gmail.com \\ 3* Network of Disaster Management Practitioners (Pvt) Ltd, Islamabad, Pakistan; \\ falak@pakndmp.com \\ ${ }^{4}$ Dept. of Education, Azad Jammu and Kashmir, Muzaffarabad, \\ adnan_ajk@hotmail.com
}

KEY WORDS: Participatory rural appraisal (PRA) tools, Flood inundation, Hazard assessment, Geographical information system (GIS), Remote sensing (RS).

\begin{abstract}
:
Unexpected growth of population and urbanization eventually leads towards disasters, might be natural or manmade for instance climate change, the rise in sea level, pollution, landslides, floods, etc. Subsequently, floods are the worst effects of agricultural revolution and comes up as a potential most natural hazard in the world. It couldn't be stopped but the adverse impact can be minimized through structural and non-structural measures. Flood hazard mapping have a vital role and is an essential element of land use and pre-disaster planning. Moreover, the Earth Observation (EO) data can help to prepare the updated flood hazard maps by distant viewing. Pakistan have one of the greatest irrigation systems of the world and is the sixth largest populous country. However, having such a huge irrigation system is also a threat to overflow in heavy rains. The monsoon season in 2010 , the unexpected heavy rainfall caused a massive flood which ultimately destroyed the agriculture, infrastructure in several districts all over the country. District Charsadda was affected severely by both riverine floods and flash floods in 2010. Furthermore, the floodplains of district is occupied by dense population showing the immense need to assess hazard zones to avoid additional losses. In this case study for the catchment area of River Kabul and River Swat, Charsadda, the flood hazard was identified using participatory approach and weighted overlay method. Results depict that more than $80 \%$ of the area was inundated during 2010 devastating flood in the UC Agra.
\end{abstract}

\section{INTRODUCTION}

\subsection{Background}

Geophysical hazard refers to the naturally occurred event, incidence or phenomenon which effect the human and environment negatively. It includes geological, geomorphological and metrological phenomenon's, i.e. earthquakes, tsunamis, landslides, floods, volcanic eruptions, severe storms, tornadoes, droughts and many more (Strupler et al.,2018). These events are sudden and unexpected and cause the disruption in the balance of topography, life and environment. Flood is one of the major disaster to which all South Asian countries are exposed. Particularly, in last few decades the magnitude and frequency of floods increased many folds by reason of climate changes.

Flood is one of the most sudden, distressing and frequently occurred event all over the world in relation with life and property losses. The Asian countries e.g. Pakistan, Bangladesh, Malaysia, Philippines and China are the affected most countries by sever flood each year. According to Global assessment report 2009, approximately 19 million people in Bangladesh and 58 lakh people in Pakistan are exposed to flood.

The devastating flood of 2010 in Pakistan overwhelmed onefifth of the entire country and the reported human causalities were around 2000, while the economic losses were about 20 million (Ziegler et al., 2012). These facts illustrate that the effects of flood are more drastic in developing countries as compare to developed countries. Osti (2008) mentioned that the damages from flood, in underdeveloped countries increases many folds because of poverty cycle phenomena.

Flood is a transient layer of water comes out from its regular channel due to certain reason. It is the common most critical disaster amongst all-natural disasters having drastic impact in vast area specially in plains and urban density areas. The vital reasons of flooding include heavy rainfall, glacial melting due to climate change, blockage of drainage path with trash, construction of buildings across water channels, inadequate drainage networks, and increasing population or urbanization around water channels (Ahmad, Kazmi, and Pervez, 2011).

However, individually these factors are less disasters as compare to the combination of some of these causes intensified flood disaster. Furthermore, the construction around regular water channels, change in land use/ landcover (LULC) pattern and increasing population density or urbanization in active flood plains or river beds threaten the lives of people severely (Ahmad, Hussain and Iqbal, 2010). Hence, flood is amongst the most devastating natural hazards which threaten the lives and property and causing abrupt socio-economic damages (Ahmed, 2013). 


\subsection{Flood Hazard Mapping}

To minimize the deadly effects of floods the hazard maps are crucial. It is the first and foremost step for flood risk assessment (Haq, 2011; Houze et al., 2011). The damages of flood could be minimized by preparing flood inundation maps for vulnerable areas (Hussain et al., 2010). Moreover, these maps are essential for emergency action plans, municipal planning, development and construction around the flood overstressed areas (Khan, Iqbal and Yosufzai. 2011).

The geographical information system (GIS) along with remote sensing (RS) data is a momentous tool for prompt flood hazard mapping. Additionally, it might efficiently be utilized to categorize damage information, hazard assessment and monitoring in post-disaster situation. It could also be used to model reconstruction scenario by using damage information along with census information. Moreover, the earth observation (EO) data including satellite images and digital elevation models (DEMs) are the major data base to get information about topography which is valuable to assess numerous geohazard modelling for instance hydrologic modeling, simulation of flood plain etc. The numerous derivatives of DEM (slope, aspect, flow accumulation, drainage basin etc.) allows to assess the hazard in detail caused by flood in a particular area and its future prediction.

\subsection{Flood Situation in Pakistan}

Nearly all over the world flood has been reported as hazard with prominent impact in the developing countries (Alcántara-Ayala, 2015; UNISDR, 2015a). Pakistan is severely prone to different natural hazards including landslides, floods and earthquake as majors. Being agricultural country Pakistan has one of the largest and organized river/ canal system but because of lack of sustainability, millions of people get effected by floods each year around these rivers and canals in the major part of the country. Consequently, summer floods are very common in three major provinces, Khyber Pakhtunkhwa, Punjab and Sindh of Pakistan due to monsoon season but the year 2010's brought the worst flood in Pakistan of the centuries. In addition, all the previous records have been broken for the amount of rainfall, discharge, and damage to life and property by the 2010's flood.

Almost every metrological station received above normal rainfall. Furthermore, the patterns from current years suggested the intensity of flood occurring are continuously increasing and might persist more violently during the coming years. The main cause for flooding is high magnitude of the monsoon rains due to known climatic changes in the region. Keeping an eye on the situation the flood risk assessment on country level was crucial.

In Khyber Pakhtunkhwa (KPK) province of Pakistan flooding is a regular hazard, almost every year along the banks of Kabul River (Shabir, 2013). Furthermore, in 2010 floods, KPK was the affected most province of Pakistan. The major cause of flooding in the area was monsoon rains which started on 27 July till 29 July 2010. Moreover, this rain period triggered a critical flood in the district Charsadda, KPK. On the other hand, flash floods throughout summer season is also a regular environmental hazard in district Charsadda. Two major rivers, river Kabul and river Swat exposed the district Charsadda to flooding with intense monsoon rainfall, around 200-280 millimetres. The rainfall occurred in the neighbouring areas of Peshawar, Nowshera and Charsadda which caused a very high flood stage (221,000 Cusecs) in Kabul River and remains till
August 8, 2010 (Ahmad, Bokhari and Siddiqui, 2011). Due to intensive agriculture and lack of maintenance of river and canal system the stacking of huge deposit in the water channels is very common in Pakistan which ultimately resultant as overflow of these channels. Similarly, Urbanization along major water channels is also a leading factor of rising floods in the country.

The study consists of two parts (i) hazard assessment and (ii) future prediction. this study aims to produce a comprehensive hazard map for the four villager of UC Agra District Charsadda, Pakistan using GIS/ RS techniques. This study will play as milestone to assess the vulnerability and risks of climatic changes and weather-related hazards, to which the communities are exposed. Finally, flood flows of different return periods were simulated using a hydraulic model.

The Article comprises on five sections. Section one includes background of the study, flood situation in Pakistan and need of flood hazard mapping. Moreover, section two contains the physical, climatic and demographic information of study area. Consequently, Section three explains the detailed methodology used for this study and in section four results are discussed. Finally, section five encompasses the conclusion of the study.

\section{STUDY AREA}

\subsection{Physiographic Setting}

Union Council Agra is bounded by main rivers i.e. River Kabul and Rivers Swat and two tributaries called as Khialey and Jinday rivers. There are two major roads passing through UC Agra - on eastern side is the Motorway and on northwest side Charsadda-Peshawar Road (G.T. Road), a provincial road. Three tertiary roads upstream of Kabul and swat rivers from G.T. road provide access to the villages as well as work as a second line of defense during the floods. Agra Payan-Gulabad and Jamat-Shabarha roads provide protection to the villages during floods.

The total road length is 76 kilometers in UC Agra, majority of population use motorcycles and bicycles as means of transportation. Majority of the residents are using G.T. road for travel to Charsadda and Peshawar districts (Map 1). The main source of livelihood is agriculture employment in major cities and overseas. In addition to this many people work in the fish huts located in the doaba (land between two rivers) along the GT road which is a hotspot for tourist's attraction.

\subsection{Area and Population}

The total area of Agra UC is comprised of $43.6 \mathrm{sq} . \mathrm{km}$ with a total population of 26,290 . The population density is around 603 persons/Sq. $\mathrm{km}$. There are 3,807 household with an average family size of seven persons. Out of the total population, $36.75 \%$ are adult's male, $28.22 \%$ are adult's females, $25 \%$ are children and disable population is about $1.8 \%$. The sex ratio is about 108 females per 100 males. The overall literacy ratio is $31.10 \%$.

\subsection{Soil}

The soil of Kabul River in the study area is calcareous whereas the soils developed by Swat River are non-calcareous. The alluvium soils developed from Swat River are deep, silt loam to 


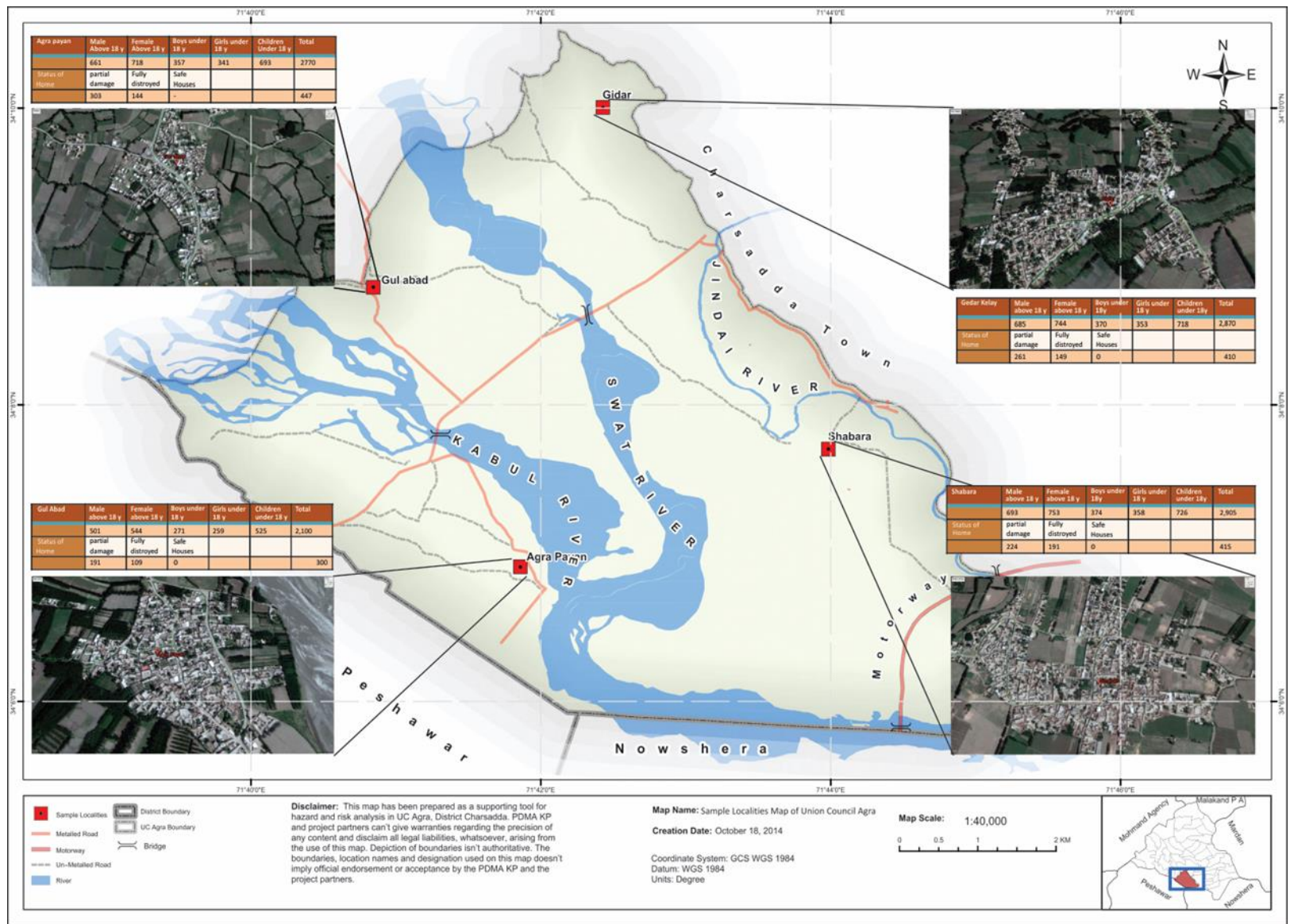

Figure 1. Location map of four selected villages in UC Agra, District Charsada, KPK, Pakistan.

\begin{tabular}{|l|l|}
\hline \multicolumn{1}{|c|}{ Total area } & \multicolumn{1}{c|}{ 43.6 Sq. Km } \\
\hline Population 2013 & 26,290 \\
\hline Population density & 603 per sq. km \\
\hline Total housing units & 3,807 \\
\hline Average household size & 7 persons \\
\hline Male population & 9,662 persons (36.75\%) \\
\hline Female population & 10,049 persons (38.22\%) \\
\hline Children population under 10 years & 6,579 persons $(25 \%)$ \\
\hline Disabled population & 461 persons (1.8\%) \\
\hline Sex ratio (males per 100 females) & 107.9 \\
\hline Overall literacy ratio (10 +) & $31.10 \%$ \\
\hline Male literacy ratio & $46.90 \%$ \\
\hline Female literacy ratio & $14.10 \%$ \\
\hline
\end{tabular}

Table 1. Basic information about UC Agra. (Source: LSO Nangyal Agra and District Census Report 1998, Pakistan Bureau of statistics, Government of Pakistan)

silty clay loam, well drained with olive dark greyish brown colour. The alluvium soils developed from the Kabul River are very deep, well drained, silt loam with olive grey colour.

\subsection{Climate}

The climate of the UC Agra and surrounding areas is extremely hot during the summer and very cold during the winter season. It varies from semi-arid to sub-humid, continental, and subtropical. The summer season persist from May to September.
June is extremely hot and dry when the temperature crosses $40^{\circ} \mathrm{C}$. Monsoon season is spread over July to September (Table 2). The month of July and August are hot and humid. The

\begin{tabular}{|c|c|c|c|c|}
\hline \multirow[t]{2}{*}{ Month } & \multicolumn{2}{|c|}{ Mean Temperature $\left({ }^{\circ} \mathrm{C}\right)$} & \multirow{2}{*}{$\begin{array}{c}\text { Precipitation } \\
\text { (millimeter) }\end{array}$} & \multirow{2}{*}{$\begin{array}{c}\text { Relative } \\
\text { Humidity }\end{array}$} \\
\hline & Maximum & Minimum & & \\
\hline January & 18.30 & 4.00 & 26.00 & 58.60 \\
\hline February & 19.50 & 6.30 & 42.70 & 57.50 \\
\hline March & 23.70 & 11.20 & 78.40 & 58.40 \\
\hline April & 30.00 & 16.40 & 48.90 & 51.70 \\
\hline May & 35.90 & 21.30 & 27.00 & 37.30 \\
\hline June & 40.40 & 25.70 & 27.70 & 36.20 \\
\hline July & 37.70 & 26.60 & 42.30 & 55.00 \\
\hline August & 35.70 & 25.70 & 67.70 & 64.60 \\
\hline September & 35.00 & 22.70 & 17.90 & 58.70 \\
\hline October & 31.20 & 16.10 & 9.70 & 54.90 \\
\hline November & 25.60 & 9.60 & 12.30 & 60.10 \\
\hline December & 20.10 & 4.90 & 23.30 & 37.60 \\
\hline Annual & 29.40 & 15.90 & 403.80 & 54.70 \\
\hline
\end{tabular}

Table 2. Mean Monthly Temperature, Precipitation and Relative Humidity (Source: District Census Report, 1998, District Charsadda)

rainfall occurs due to monsoons as well as western disturbances. The average rainfall varies from 300 to $625 \mathrm{~mm}$. On the basis of climatic data, the semi-arid zone has maximum rainfall in winter, while the sub-humid zone has a maximum monsoon rainfall in summer. 


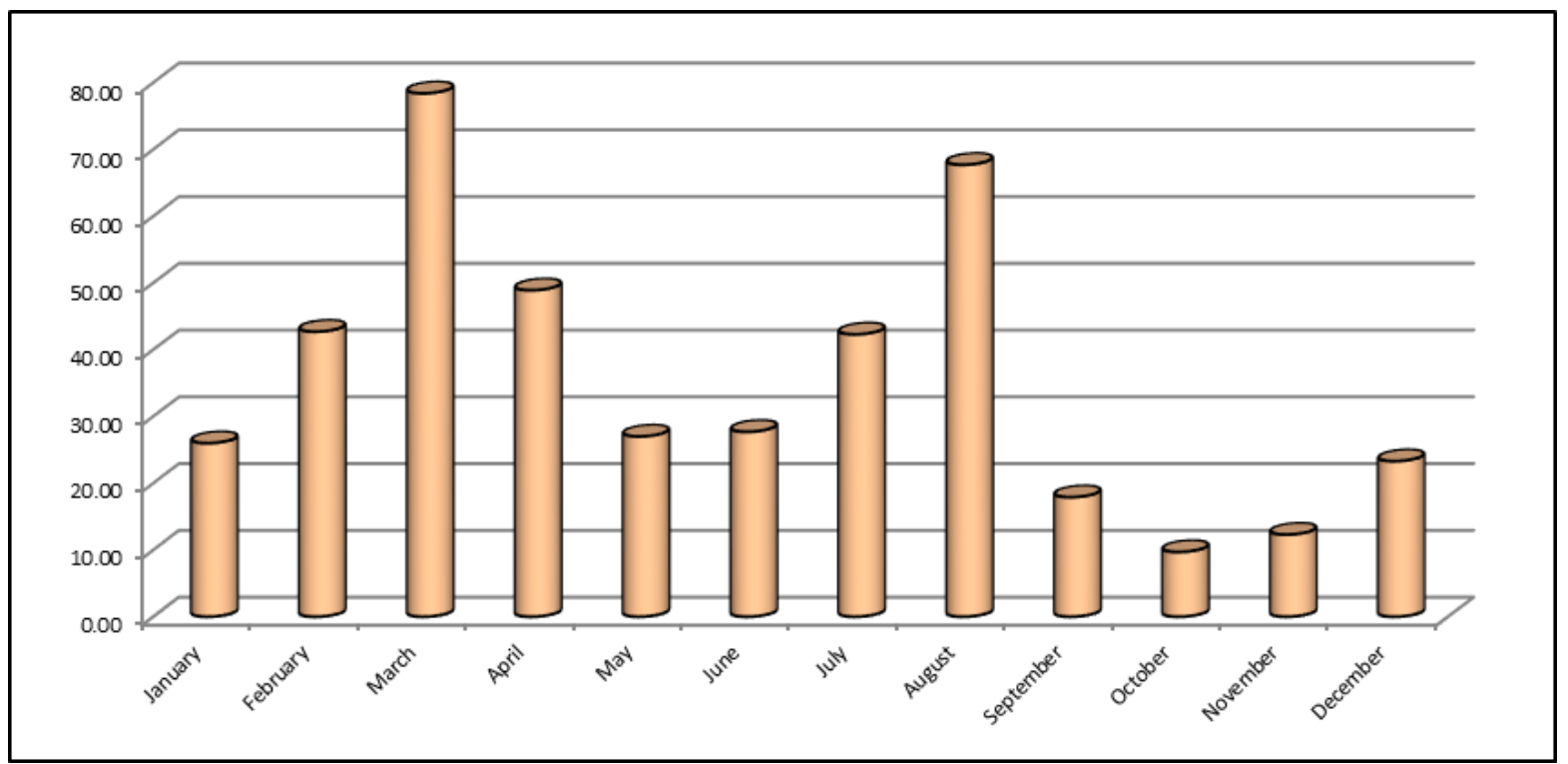

Figure 2. Average precipitation in the study area (in millimeter)

\subsection{Main Causes of Floods in District Charsadda, Pakistan}

There are several natural and anthropogenic factors participating in rising floods in District Charsadda. One of the major cause of flood in District Charsadda is heavy monsoon rainfall which did not only bring lots of water, but sediment deposition also occurs on river bed every year. Consequently, other causes including deforestation, encroachment, urbanization and lack of awareness etc. are also responsible for flood in the district.

In Pakistan usually, monsoon starts in July and continues till early September. Usually it is characterized by heavy rainfall with a short time spam which adds plenty of water in rivers and becomes difficult to accommodate. Ice melting due to sudden change in weather in the hilly areas of Chitral, Swat and Deer also contributes in floods.

The second major cause of Charsadda floods is rapidly growing population or urbanization. human-induced activities also play a key role in flood generation process. Due to intensive agricultural activities in flood-prone areas the monsoon rain washes out the surface sediments from agricultural areas and deposits them into river bed. Consequently, the drains become shallow and cannot accommodate the heavy flow of water in monsoon. That's why the water overflow the river banks and cause flood in the district. Urbanization is also playing significant role as population encroachment towards flood plains are observed. Due to rapid development in floodplains the flow of water halts.

\section{METHODOLOGY}

For comprehensive hazard assessment of Agra UC, the following steps were followed including the local topography,

land use and associated Rivers passing nearby of Union Council Agra at GIS platform. The study was completed in seven steps: a) development of database (river alignment, bridges, settlements and other associated layers); b) extraction and profiling of river and basin; c) creation of river center line, bank line, cross section; d) extraction of Land use classes from the satellite imagery; e) computation of flood levels; f) Mapping of flood inundation areas (area and depth); and g) Future prediction. The final output products are flood hazard maps with detail hazard profile for different return periods for four selected villages namely Gidar, Agra Payan, Shabara and Gulabad of the UC Agra (Figure 4, 5, 6. 7).

Hazard assessment process cover various scientific and technical approaches, including a review of past and ongoing studies and activities related to those hazards in the categories of hydrological, meteorological, and topographical phenomena. Through extensive consultation process with provincial and district level government line departments and non-government organizations and community stakeholders, the primary data were collected in order to analyze the historical hazards and disasters catalogue and the geographical extent. Data gaps, alternative sources, verification of hazard assessments have been completed during different field surveys through various participatory rural appraisal (PRA) tools. The ultimate results were then transferred into better visual interpretation models using different mapping techniques.

\subsection{Tools used for Hazard Assessment}

\subsubsection{PRA based Hazard Assessment:}

The data was mainly collected through intensive field surveys using PRA tools with the village volunteers and enumerators. Data was collected from different villages and tools like social mapping, hazard mapping, historical profile, seasonal calendar, transect walk, direct observation, key informant interviews and focus group discussions (FGDs) were used to get maximum information about flood and other associated secondary hazards in past and in recent years. Data collected for the proposed study and analyzed through various techniques of GIS to get the maximum accurate results. 


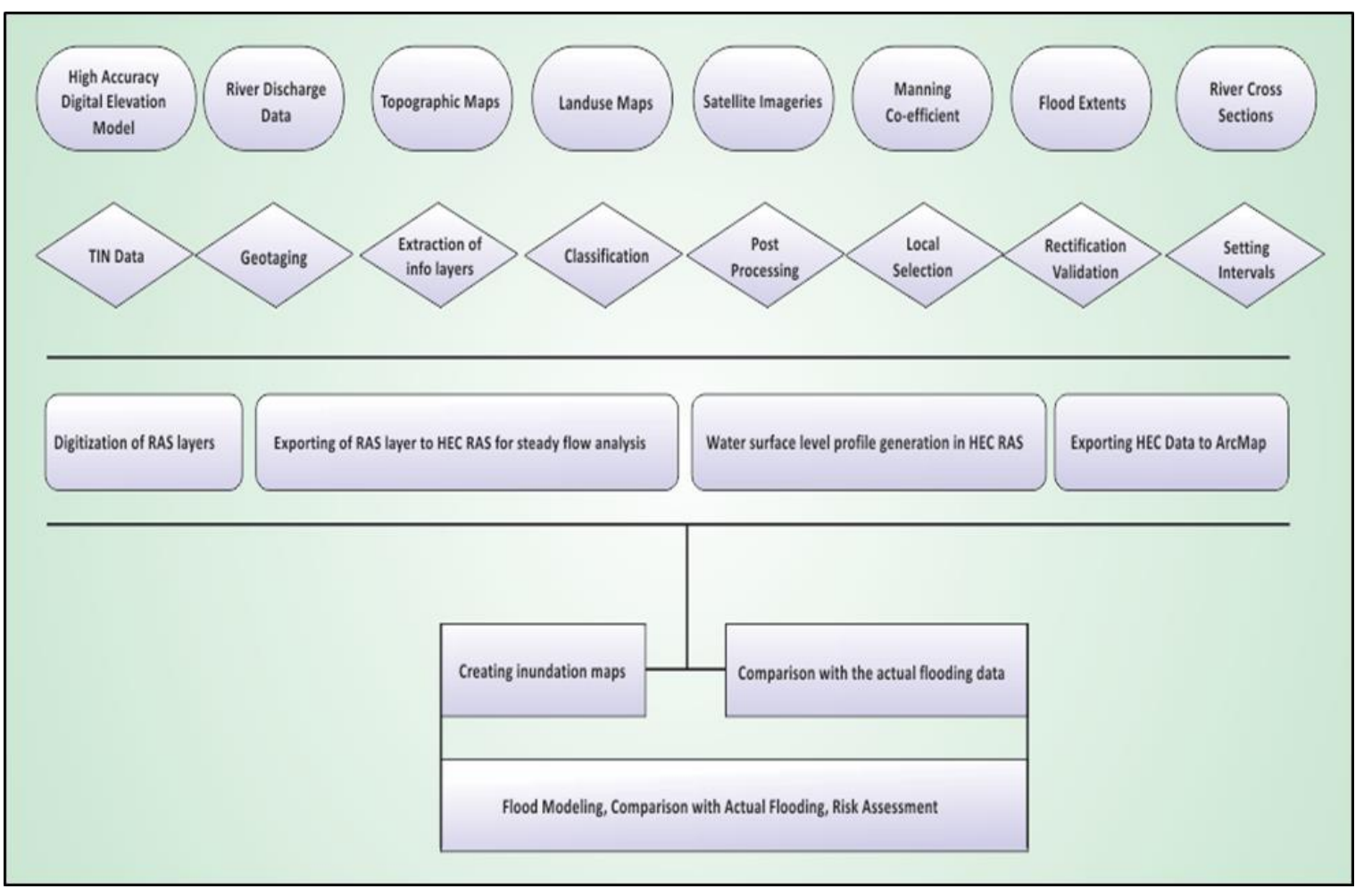

Figure 3. Process followed for developing classified flood hazard map

\subsubsection{Historical event-based hazard assessment (Flood 2010):}

Historical events data sources were utilized to collect data about past flood disasters, their damages and extent. Such data in refined form was not available with district government authorities, however, data collected from other relevant organizations including Pakistan Meteorological Department (PMD), Irrigation Department, University of Peshawar, SUPARCO and PDMA Khyber Pakhtunkhwa was available. Based on available secondary sources, flood 2010 inundation map was prepared based on the available record. Results depict that more than $80 \%$ of the area was inundated during 2010 devastating flood. Data collected through secondary sources were carefully cross-checked during field surveys through PRA tools. The model-based results were calibrated from these records.

\section{RESULTS AND DISCUSSIONS}

\subsection{Flood Modelling:}

The data base for flood modelling for example, river alignment, bridges, settlements and other associated layers were prepared through digitization while the river profile, river basin, creation of river center line, bank line, cross section were extracted with the help of GIS platform. The land use was extracted from satellite imagery and analysis of flood hazard and risk assessment has been done at GIS platform. The mapping of flood inundation areas (area and depth) has been done and it was projected on future scenarios. There are three outputs for future projection with return period of 10 year, 30 years and 100 years.

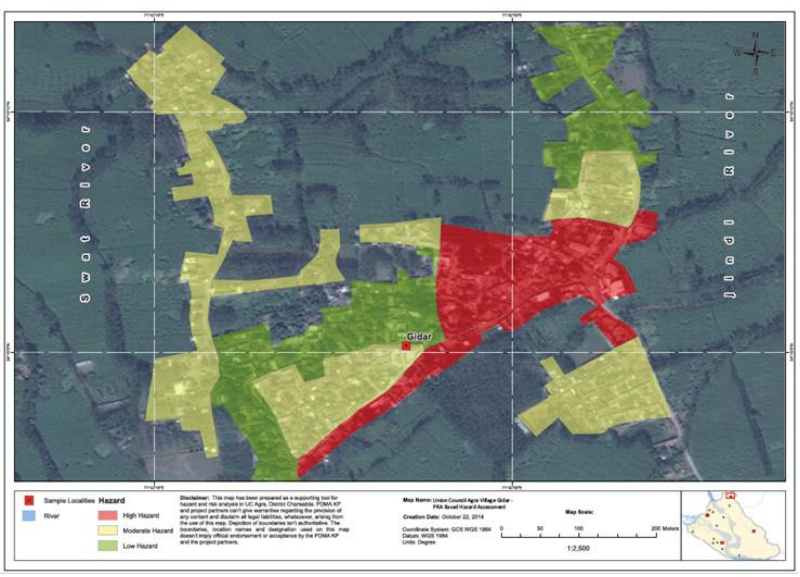

Figure 4. Flood hazard assessment for Village Gidar

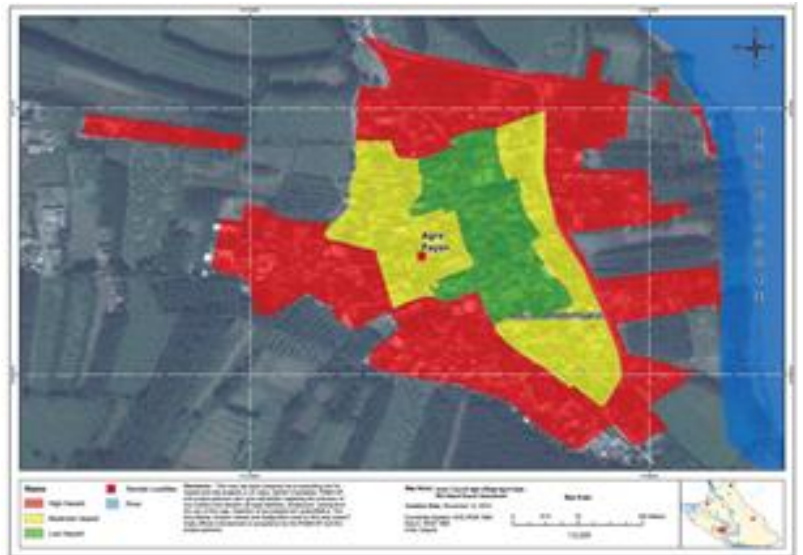

Figure 5. Flood hazard assessment for Village Agra Payan 
The International Archives of the Photogrammetry, Remote Sensing and Spatial Information Sciences, Volume XLII-4/W16, 2019 6th International Conference on Geomatics and Geospatial Technology (GGT 2019), 1-3 October 2019, Kuala Lumpur, Malaysia

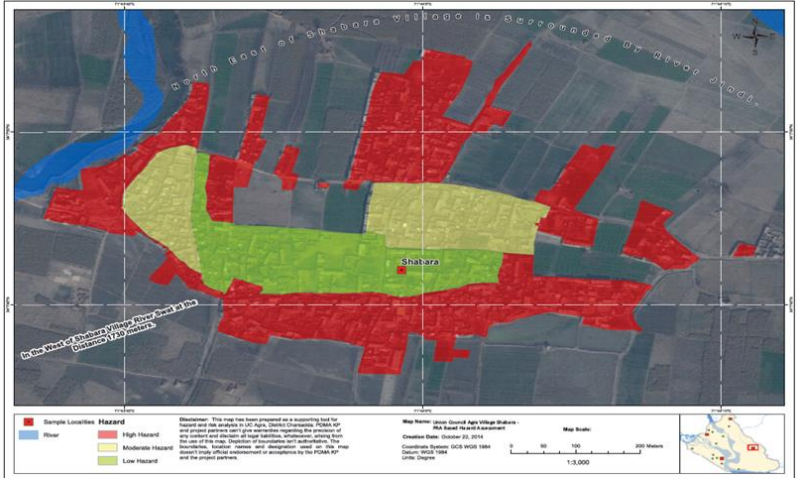

Figure 6. Flood hazard assessment for Village Shabara

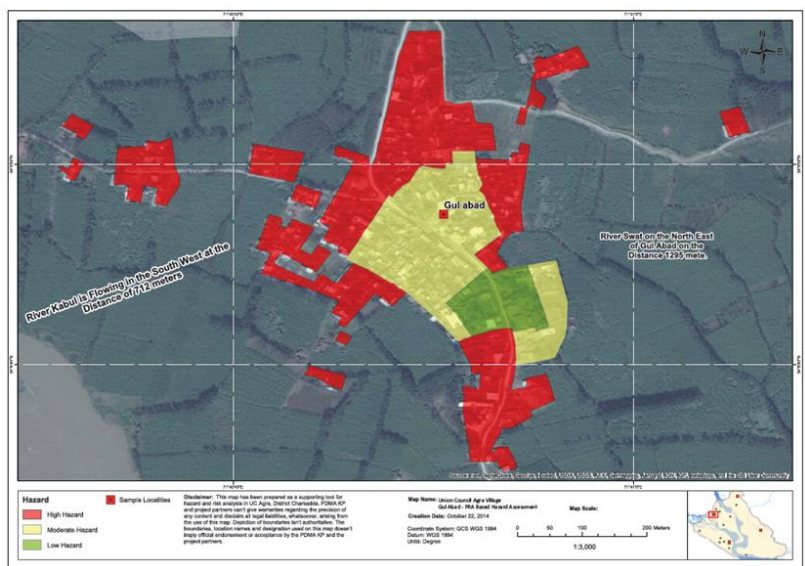

Figure 7. Flood hazard assessment for Village Gul Abad

The flood hazard maps for all four villages were prepared. Except Village Gidar in rest three villages Agra Payan, Shabara and Gul Abad more than 50 percent of the area is under high flood hazard threat. Most of the residential area Is under high hazard threat. In village Gidar around 50 presents of the land is under medium flood hazard zone while 30 percent of the land is under high hazard zone.

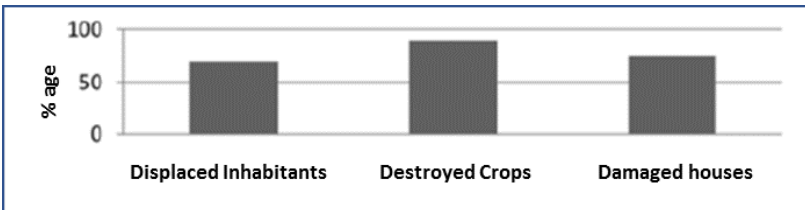

Table 3. Social and physical infrastructure in UC Agra

According to Islamic relief organization in 2010 flood almost $90 \%$ of the crops of union council Agra were destroyed. Furthermore, around $75 \%$ of houses were destroyed and almost 70 percent of the total population was displaced.

The Flood inundation map on 10 years return period is depicting that with increase in population the intensity of flood hazard might be severe along Kabul river and at the confluence point of river Swat and Kabul. Village Agra Payan will be the vulnerable most village for flood hazard with flood level of around 3 to 5 feet while village shabara is also in more or less same situation. Village Gul abad is vulnerable to low to medium risk of flooding and village Gidar have low hazard zone.

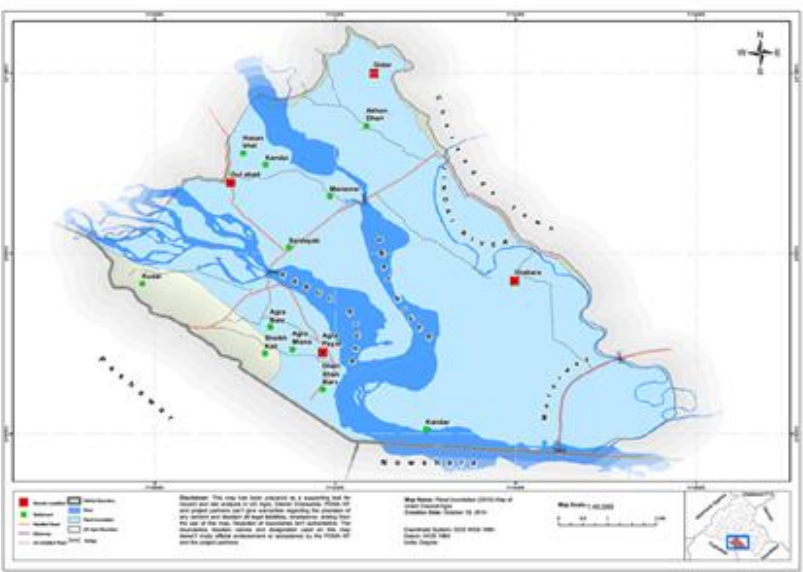

Figure 8. UC Agra - 2010 flood inundation map 2010

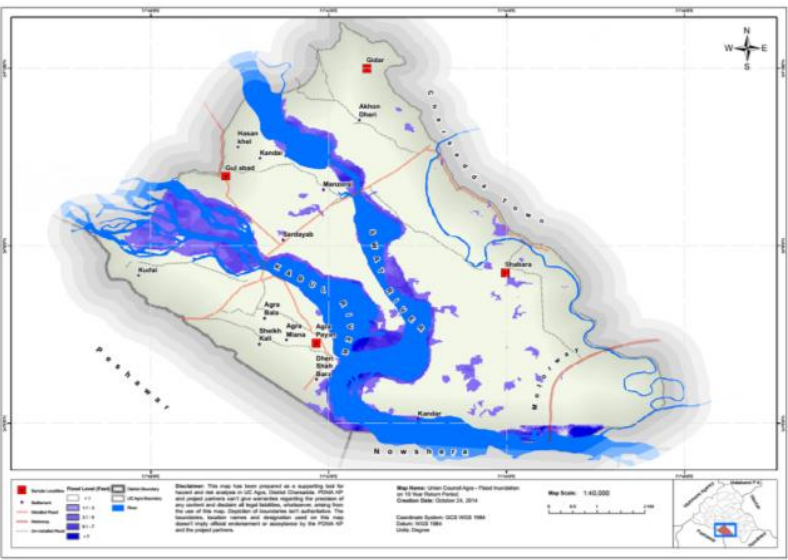

Figure 9. Flood inundation map on 10-year return period

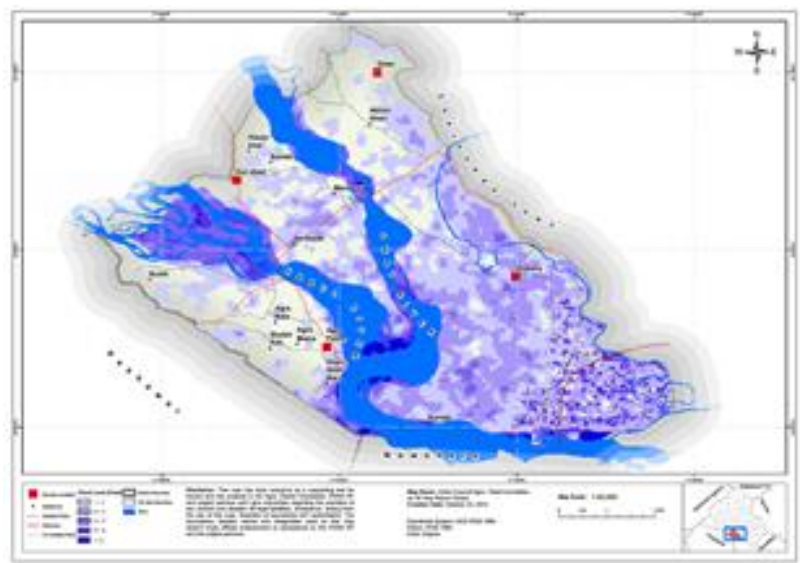

Figure 10. Flood inundation map on 30-year return period

The flood inundation map with 30 years return period is illustrating that the whole Union Council could be under low to medium flooding especially the area covered by motorway 


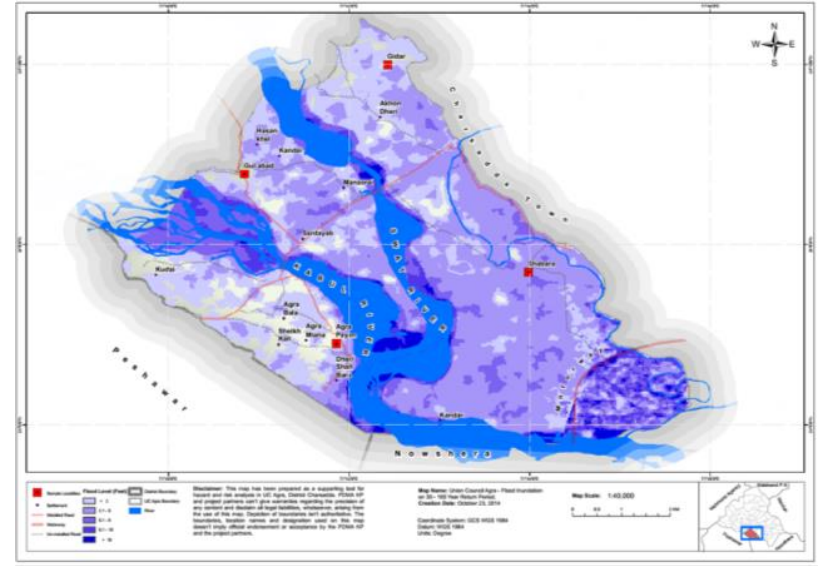

Figure 11. Flood inundation map on 100 years return period

might be under high flooding in rainy season. The 100 years return period flood inundation map is describing even worse situation as the UC Agra might be under medium to hig flooding due to urbanization and deforestation.

\section{CONCLUSION}

Floods are the frequent most natural hazard in district Charsadda due to presence of two main rivers Swat and Kabul and two tributaries Khialey and Jinday rivers. The Agra UC is located approximately eighteen kilometers from the provincial capital of Peshawar. The flood in 2010 was the disastrous most in throughout the flooding history of Pakistan both natural and anthropogenic factors contributed to this disaster including sedimentation at river beds, deforestation, terrain, extreme rainfall, rapidly increasing population, unplanned development at the banks of rivers and inefficiency of government etc. It has observed during the field study that these rivers and its tributaries do not have appropriate flood protection works at the concerned UC to check the over spilling of the rivers during flooding.

In addition to the damage to the standing crops and immovable and movable assets, access to drinking water for humans, as well as animals is severely impaired, coupled with lack of access to sanitation facilities. During flooding, the communities take refuge on higher grounds till the water is retreated. During this period the communities have limited access to clean drinking water and suffer from poor sanitary conditions causing spread of water borne diseases especially the main victims are women and children.

As mentioned above that UC Agra is located at the confluence of three rivers - Kabul, Swat and Khialey Rivers. Almost every year during the monsoon season with the rise of water level in these rivers, the area gets flooded, causing damage to residential and agricultural land and inundating water and sanitation facilities. Communities normally rely on their own traditional coping mechanisms and survival strategies and have not yet developed disaster preparedness, mitigation and prevention to any significant degree.

It has been observed that communities in the Agra UC are more frequently affecting due to frequent flooding in these rivers. Climate change and global warming are serious concerns increasing UC Agra flood risk. Huge surge of water observed frequently even during April when glacier melting starts at the mountainous areas of Northern Khyber Pakhtunkhwa from where river swat is originating, although hardly any rain in the upper Khyber Pakhtunkhwa and down in Peshawar basin observed during April.

One another important reason for more frequent flooding is the construction of motorway which restricted the flow and velocity of these rivers during flooding. The floods in 2010 is a classic example when the motorway acts as barrier and all flood water ponded at the motorway in UC Agra, as a result more than $80 \%$ of the UC was under flooded.

To reduce the risk from flood in the district it is important to involve the community to participate in policy-making and at implementation level. Because the local communities are well aware of the main problems facing the society and might suggest better solutions for planning and mitigation.

\section{REFERENCES}

Ahmed, Z., 2013. Disaster risks and disaster management policies and practices in Pakistan: A critical analysis of Disaster Management Act 2010 of Pakistan. International Journal of Disaster Risk Reduction, 4, 15-20.

Ahmad, H., Bokhari, J. B., and Siddiqui, Q. T. M., 2011. Flashflood riskassessment in Pakistan. Pakistan Engineering Congress,71st Annual Session Proceedings. 2011;Paper No.707:696-708.

Ahmad, F., Kazmi, S. F., and Pervez, T., 2011. Human response to hydro-meteorological disasters: A case study of the 2010 flash floods in Pakistan. Journal of Geography and Regional Planning, 4 (9), 518.

Ahmad, F., Hussain and Iqbal, B., 2010. Flood Risk Assessment in Pakistan. Pakistan Engineering Congress, 71 (9), 697-707.

Alcántara-Ayala, I., O. Altan, D.N. Baker, S. Briceño, S.L. Cutter, H. Gupta, A. Holloway, A. Ismail-Zadeh, V. JiménezDíaz, D. Johnston, G.A. McBean, Y. Ogawa, D. Paton, E. Polio, R.K. Silbereisen, K. Takeuchi, G.B. Valsecchi, C. Vogel, G. Wu and P. Zhai., 2015. Disaster Risks research and assessment to promote risk reduction and management, ICSUISSC Ad-hoc Group on Disaster Risk Assessment, In: IsmailZadeh, A. and S.L. Cutter (eds.) ICSU-ISSC, 47 pp. ( http://www.icsu.org/science-for-policy/disaster )

Haq, Ul. Ehsan., 2011. Community response to climate hazard in Northern Pakistan. Maintain Research and Development, 27 (4), 308-312.

Houze Jr, R. A., Rasmussen, K. L., Medina, S., Brodzik, S. R., and Romatschke, U., 2011. Anomalous atmospheric events leading to the summer 2010 floods in Pakistan. Bulletin of the American Meteorological Society, 92 (3), 291-298.

Hussain, I., Spock, G., Pilz, J., and Yu, H. L., 2010. Spatiotemporal interpolation of precipitation during monsoon periods in Pakistan. Advances in Water Resources, 33, 880886. 
ISDR., 2009. Global Assessment Report on Disaster Risk Reduction. United Nations, Geneva, Switzerland.

Khan, B., Iqbal, M. J., and Yosufzai, M. A. K., 2011. Flood risk assessment of river Indus of Pakistan. Arabian Journal of Geosciences, 4 (1-2), 115-122.

Osti, R., Tanaka, S., and Tokioka, T., 2008. Flood hazard mapping in developing countries: problems and prospects. Disaster Prevention and Management: An International Journal, 17(1), 104-113.

Strupler, M., Danciu, L., Hilbe, M., Kremer, K., Anselmetti, F. S., Strasser, M., and Wiemer, S., 2018. A subaqueous hazard map for earthquake-triggered landslides in Lake Zurich, Switzerland. Natural Hazards, 90(1), 51-78.

Shabir, O., 2013. A Summary Case Report on the Health Impacts and Response to the Pakistan Floods of 2010. PLoS Currents, 5, ecurrents. dis.cc7bd532ce252c1b740c39a2a 827993f. http://doi.org/10.1371.

UNISDR., 2015a. Global Assessment Report on Disaster Risk Reduction 2015. Geneva: United Nations International Strategy on Disaster Reduction.

Ziegler, A. D., Lim, H. S., Tantasarin, C., Jachowski, N. R., and Wasson, R., 2012. Floods, false hope, and the future. Hydrological Processes, 26(11), 1748-1750.

Revised August 2019 